\title{
Clinical Implications of Serial Changes in ST-Segment Elevation After Reperfusion in Patients With Anterior Acute Myocardial Infarction
}

\author{
Jun Okuda, MD; Masami Kosuge, MD; Toshiaki Ebina, MD; Kiyoshi Hibi, MD; \\ Kengo Tsukahara, MD; Noriaki Iwahashi, MD; Mitsuaki Endo, MD; \\ Tatsuya Nakachi, MD; Takayuki Mitsuhashi, MD; Fumiyuki Otsuka, MD; \\ Ikuyoshi Kusama, MD; Katsutaka Hashiba, MD; Naohiro Komura, MD; \\ Satoshi Umemura, MD; Kazuo Kimura, MD
}

\begin{abstract}
Background In patients with acute myocardial infarction (AMI), the relationship of serial changes in STsegment elevation after reperfusion to left ventricular (LV) function remains unclear.

Methods and Results The study group comprised 164 patients with reperfused anterior AMI within $6 \mathrm{~h}$ of symptom onset. The sum of ST-segment deviation was calculated on admission ( $\Sigma$ ST-admission), and $1 \mathrm{~h}(\Sigma \mathrm{ST}$ $1 \mathrm{~h})$ and $24 \mathrm{~h}\left(\sum \mathrm{ST}-24 \mathrm{~h}\right)$ after reperfusion. ST resolution was defined as a reduction in $\sum \mathrm{ST}-1 \mathrm{~h}$ of $\geq 50 \%$ as compared with $\Sigma$ ST-admission. Patients were classified into 3 groups: group A, 82 patients with ST resolution in whom $\sum$ ST- $1 \mathrm{~h} \geq \sum$ ST-24h; group B, 37 patients with ST resolution in whom $\sum$ ST- $1 \mathrm{~h}<\sum$ ST-24h; group $\mathrm{C}, 45$ patients without ST resolution. Peak creatine kinase were higher in groups B and C than in group A $(4,578 \pm 2,176,4,236 \pm 2,638,2,222 \pm 1,926 \mathrm{mU} / \mathrm{ml}, \mathrm{p}<0.01)$. At 6 months follow-up, the $\mathrm{LV}$ ejection fraction were lower in groups B and C than in group A $(53 \pm 8,54 \pm 12,62 \pm 9 \%, \mathrm{p}<0.01)$.

Conclusions An increase in ST-segment elevation 1-24h after reperfusion, despite ST resolution, is associated with a larger infarction and poorer LV function in patients with reperfused anterior AMI. (Circ J 2008; 72: 409-414)
\end{abstract}

Key Words: Electrocardiogram; Myocardial infarction; ST-segment

$\mathbf{T}$ he main goals of reperfusion therapy for acute myocardial infarction (AMI) are early, sustained patency of the infarct-related artery (IRA) and optimal microvascular reperfusion!-6 Recent studies have shown that resolution of ST-segment elevation (ST resolution) on the 12-lead electrocardiogram (ECG) after reperfusion is associated with adequate microvascular perfusion in AMI and may predict smaller infarct size, better left ventricular (LV) function, and better outcomes?-10 However, we previously reported that some patients have a larger infarct size, LV dysfunction, and inadequate myocardial perfusion despite ST resolution, suggesting that ST resolution does not consistently predict myocardial salvage ${ }^{11}$ Moreover, Brodie et al reported a poorer correlation between ST resolution and late cardiac mortality in anterior myocardial infarction (MI) than in the non-anterior type! ${ }^{2}$ To clarify the clinical significance of ST resolution in more detailed, we examined the relationship between ST-segment changes up to $24 \mathrm{~h}$ after reperfusion and LV function in patients with reperfused anterior wall AMI.

(Received May 21, 2007; revised manuscript received October 28, 2007; accepted November 15, 2007)

Division of Cardiology, Yokohama City University Medical Center, Yokohama, Japan

Mailing address: Kazuo Kimura, MD, Division of Cardiology, Yokohama City University Medical Center, 4-57 Urafune-cho, Minami-ku, Yokohama 232-0024, Japan. E-mail: c-kimura@urahp. yokohama-cu.ac.jp

All rights are reserved to the Japanese Circulation Society. For permissions, please e-mail: cj@j-circ.or.jp

\section{Methods}

\section{Study Population}

We studied 164 consecutive patients (mean age $62 \pm 11$ years, range 30-86; 134 men, 30 women) with anterior AMI who were admitted to hospital and fulfilled the following criteria: (1) reperfusion (defined as restoration of Thrombolysis In Myocardial Infarction (TIMI) grade 3 flow) of the left anterior descending artery within $6 \mathrm{~h}$ of symptom onset and persistent patency of the IRA at a mean of 14 days and 6 months as confirmed by coronary angiography (CAG); (2) absence of conditions precluding the evaluation of ST-segment changes on ECG (eg, left or right bundle branch block, ventricular pacing); (3) ECG recorded on admission and at $1 \mathrm{~h}$ and $24 \mathrm{~h}$ after reperfusion; (4) absence of cardiogenic shock on admission. Patients with a re-elevation of serum creatine kinase (CK) (ie, re-infarction) during hospitalization were also excluded, because re-occlusion of the IRA could cause recurrent ST-segment elevation. The diagnosis of AMI was based on typical chest pain lasting $\geq 30 \mathrm{~min}$, ST-segment elevation $\geq 2.0 \mathrm{~mm}$ in $\geq 2$ contiguous precordial leads, and a typical increase in the serum CK level to more than twice the upper limit of normal. Pre-infarction angina was defined as the presence of typical chest pain occurring at rest or during exercise and persisting for less than $30 \mathrm{~min}$ within $24 \mathrm{~h}$ of the onset of AMI ${ }^{13}$ The protocol was approved by the hospital's internal review board and all patients gave informed consent. 
A

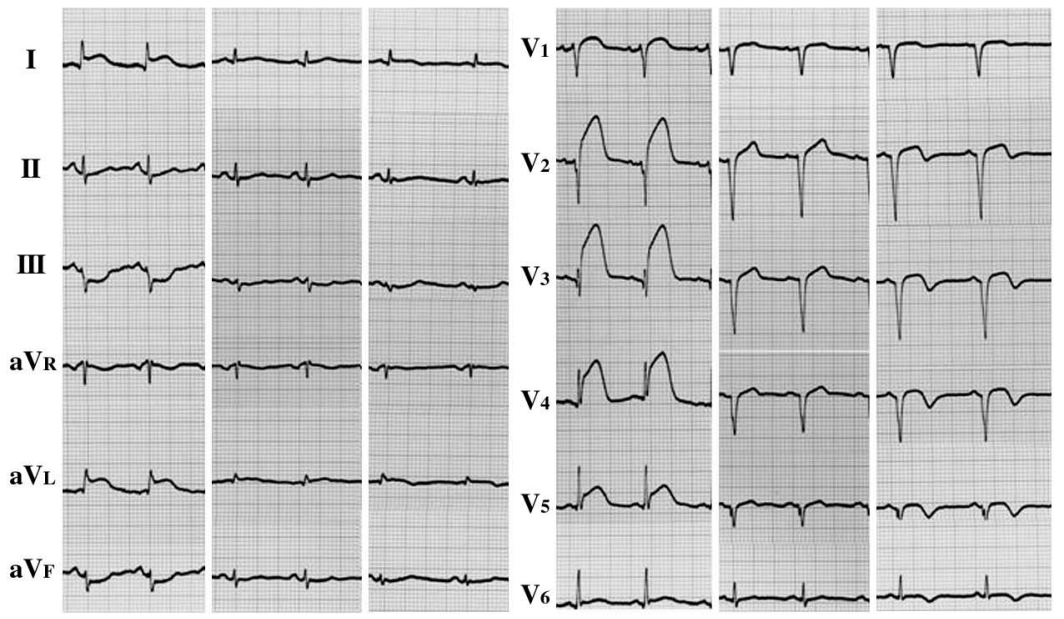

B
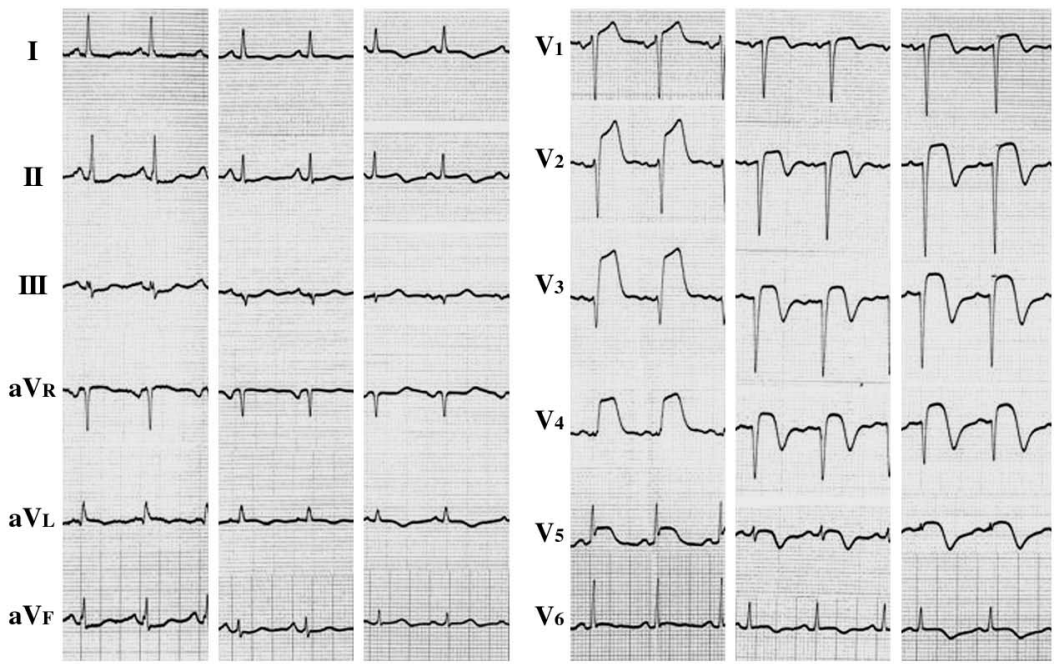

C
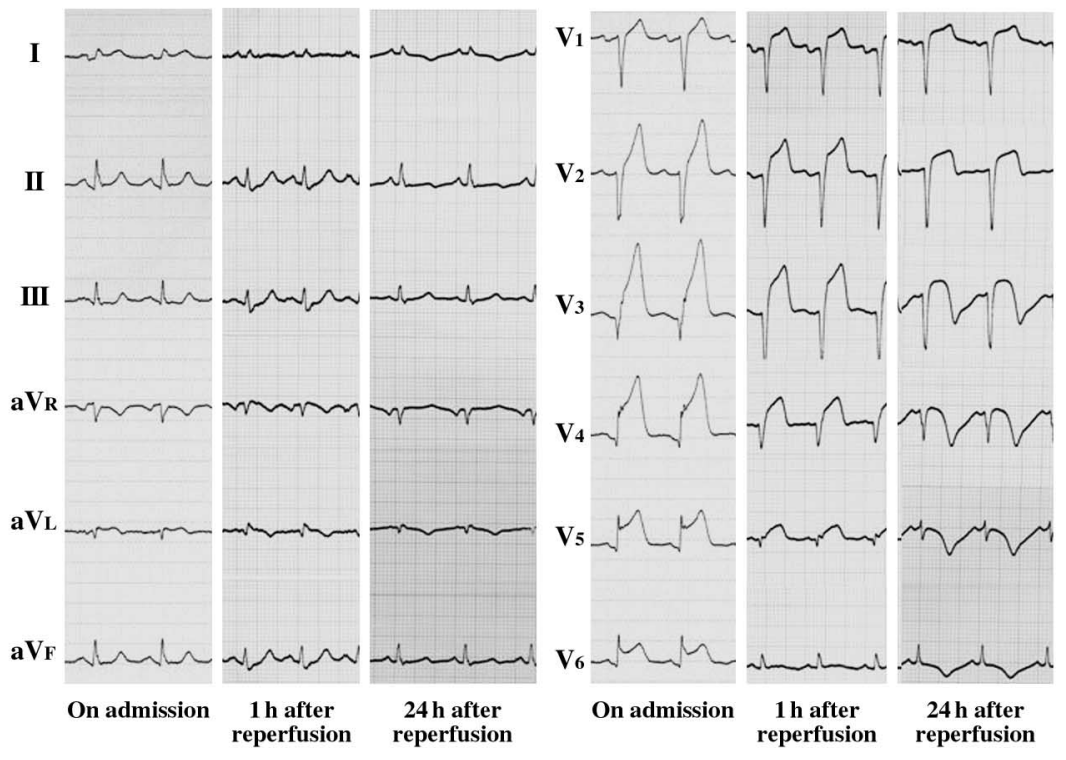

Fig 1. (A) Electrocardiograms (ECGs) from a patient with $\mathrm{ST}$ resolution in whom the $\Sigma \mathrm{ST}$ at $1 \mathrm{~h}$ was greater than the value at $24 \mathrm{~h}$ (group A). The sum of ST-segment deviation on admission ( $\Sigma \mathrm{ST}$-admission), and at $1 \mathrm{~h}\left(\sum \mathrm{ST}-1 \mathrm{~h}\right)$ and $24 \mathrm{~h}\left(\sum \mathrm{ST}-24 \mathrm{~h}\right)$ after reperfusion were 32,3 , and $2.5 \mathrm{~mm}$, respectively. The culprit lesion was segment 7 . Time from symptom onset to reperfusion was $3.1 \mathrm{~h}$. Left ventricular ejection fraction (LVEF) was $61 \%$ at 6 months later. (B) ECGs from a patient with ST resolution in whom $\Sigma S T$ at $1 \mathrm{~h}$ was less than that at $24 \mathrm{~h}$ (group B). The $\Sigma S T$-admission, $\Sigma S T-1 \mathrm{~h}$ and $\Sigma$ ST-24h were 32,9 , and $18 \mathrm{~mm}$, respectively. The culprit lesion was segment 6 . Time from symptom onset to reperfusion was $4.1 \mathrm{~h}$. LVEF was $47 \%$ at 6 months later. (C) ECGs from a patient without ST resolution (group C). The $\Sigma \mathrm{ST}$-admission, $\sum$ ST-1h and $\Sigma$ ST-24h were 28,21 , and $8 \mathrm{~mm}$, respectively. The culprit lesion was segment 6 . Time from symptom onset to reperfusion was $2.3 \mathrm{~h}$. LVEF was $54 \%$ at 6 months later.

\section{$C A G$}

CAG was performed immediately after admission and reperfusion (defined as TIMI grade 3 flow) was established by thrombolysis in 52 patients and by primary or facilitated coronary angioplasty in 98 . The grade of collateral filling in the left descending coronary artery was evaluated as de- scribed by Rentrop et al! ${ }^{14}$ A good collateral channel was defined as grade 2 or 3 . The allocation of reperfusion therapy was left to the physician's discretion. Reperfusion time was defined as that from symptom onset to the time of confirming TIMI grade 3 flow angiographically. In patients with an improvement in symptoms and a decrease in ST- 
Table 1 Baseline Characteristics

\begin{tabular}{|c|c|c|c|c|}
\hline & $\begin{array}{c}\text { Group A } \\
\text { ST resolution } \\
\sum S T-1 h \geq \sum S T-24 h \\
(n=82)\end{array}$ & $\begin{array}{c}\text { Group B } \\
\text { ST resolution } \\
\sum S T-1 h<\sum S T-24 h \\
(n=37)\end{array}$ & $\begin{array}{c}\text { Group C } \\
\text { No ST resolution } \\
(n=45)\end{array}$ & $p$ value \\
\hline Age (years) & $60 \pm 11$ & $64 \pm 11$ & $63 \pm 12$ & 0.07 \\
\hline Men & $70(85 \%)$ & $28(76 \%)$ & $37(82 \%)$ & 0.44 \\
\hline Heart rate on admission (beats/min) & $81 \pm 18$ & $83 \pm 19$ & $88 \pm 21$ & 0.20 \\
\hline SBP on admission $(\mathrm{mmHg})$ & $149 \pm 29$ & $148 \pm 28$ & $149 \pm 30$ & 0.97 \\
\hline Killip $\geq 2$ on admission & $2(2 \%)$ & $2(5 \%)$ & $6(13 \%)$ & 0.048 \\
\hline Previous angina within $24 \mathrm{~h}$ before $A M I$ & $30(37 \%)$ & $10(27 \%)$ & $22(49 \%)$ & 0.11 \\
\hline Good collateral circulation* & $6 / 18(33 \%)$ & $9 / 22(41 \%)$ & $11 / 27(41 \%)$ & 0.22 \\
\hline Percutaneous coronary intervention & $33(41 \%)$ & $30(81 \%)$ & $35(77 \%)$ & $<0.001$ \\
\hline Time from symptom onset to reperfusion (min) & $139 \pm 68$ & $202 \pm 94$ & $187 \pm 108$ & 0.002 \\
\hline Current smoker & $58(71 \%)$ & $24(65 \%)$ & $26(58 \%)$ & 0.32 \\
\hline Hypercholesterolemia & $45(55 \%)$ & $19(51 \%)$ & $28(62 \%)$ & 0.61 \\
\hline Diabetes mellitus & $23(28 \%)$ & $13(35 \%)$ & $17(38 \%)$ & 0.52 \\
\hline Hypertension & $34(41 \%)$ & $21(57 \%)$ & $26(58 \%)$ & 0.16 \\
\hline Multivessel disease & $19(23 \%)$ & $12(32 \%)$ & $12(27 \%)$ & 0.61 \\
\hline Culprit lesion (segment 6) & $54(66 \%)$ & $21(57 \%)$ & $30(67 \%)$ & 0.53 \\
\hline TIMI flow grade 0 or 1 at initial angiography & $18(22 \%)$ & $22(59 \%)$ & $27(60 \%)$ & $<0.001$ \\
\hline \multicolumn{5}{|l|}{ Discharge medications } \\
\hline Aspirin & $82(100 \%)$ & $37(100 \%)$ & $45(100 \%)$ & 1.00 \\
\hline$A C E I / A R B$ & $66(80 \%)$ & $32(86 \%)$ & $37(82 \%)$ & 0.76 \\
\hline$\beta$-blocker & $39(48 \%)$ & $21(57 \%)$ & $31(69 \%)$ & 0.10 \\
\hline Statin & $54(66 \%)$ & $23(62 \%)$ & $28(62 \%)$ & 0.83 \\
\hline
\end{tabular}

*Grade 2 or 3 collateral flow to the left anterior descending coronary artery only in patients who had TIMI flow grade 0 or 1 on initial angiography.

Data are mean values $\pm S D$ or numbers $(\%)$ of patients.

$\Sigma S T-1 \mathrm{~h}$, the sum of ST-segment deviation $1 \mathrm{~h}$ after reperfusion; $\Sigma S T-24 \mathrm{~h}$, the sum of ST-segment deviation $24 \mathrm{~h}$ after reperfusion; SBP, systolic blood pressure; AMI, acute myocardial infarction; TIMI, Thrombolysis In Myocardial Infarction; ACEI, angiotensinconverting enzyme inhibitor; $A R B$, angiotensin receptor blocker; $S D$, standard deviation.

segment deviation $\left(\sum \mathrm{ST}\right)$ before cardiac catheterization in whom TIMI grade 3 flow was confirmed at initial angiography, reperfusion time was defined as that from symptom onset to the time when the improvement in symptoms and the decrease in ST-segment elevation were confirmed.

\section{Electrocardiographic Analysis}

The 12-lead ECG was recorded at a paper speed of $25 \mathrm{~mm} / \mathrm{s}$ and an amplification of $10 \mathrm{~mm} / \mathrm{mV}$. All ECGs were reviewed by an observer who was unaware of the patients' clinical data. The isoelectric line was defined as the level of the preceding TP segment. The ST-segment was measured $20 \mathrm{~ms}$ after the J point, and the sum of $\sum \mathrm{ST}$ on admission, and at $1 \mathrm{~h}$ and $24 \mathrm{~h}$ after reperfusion was calculated by previously described methods $!^{15}$ The negative value of the ST-segment elevation in the II, III, and $\mathrm{aVF}_{\mathrm{F}}$ leads were added to the positive value of the ST-segment of anterior leads. ST resolution was defined as a reduction of at least $50 \%$ in $\Sigma \mathrm{ST}$ on ECGs obtained $1 \mathrm{~h}$ after reperfusion as compared with the value on admission. The numbers of leads with ST-segment elevation $\geq 1 \mathrm{~mm}$ were measured on the admission ECG!16 The 32-point Selvester QRS score was also calculated 17 because sincebecause it has been validated in patients with AMI and strongly correlates with infarct size ${ }^{18}$ The difference in the QRS scores before and after reperfusion reflects the amount of myocardial damage related to reperfusion injury? Additional ST-segment elevation of at least $5 \mathrm{~mm}$ in leads $\mathrm{V}_{1-6}$ immediately after reperfusion was defined as additional ST-segment elevation! ${ }^{19}$

\section{Blood Samples}

Samples for measurement of serum C-reactive protein (CRP) levels were taken on admission and every $24 \mathrm{~h}$ for at least 7 days. Patients with infectious disease, collagen dis- ease, malignant disease, or severe hepatic or renal failure were excluded from the analysis of CRP levels. Samples for measurement of serum CK were taken on admission and at 3 -h intervals during the first $24 \mathrm{~h}$, at 12 -h intervals for the next 2 days, and then daily until discharge. Peak levels of $\mathrm{CK}$ and $\mathrm{CK}-\mathrm{MB}$ and the areas under the curve (AUC) for $\mathrm{CK}$ and $\mathrm{CK}-\mathrm{MB}$ as calculated by the linear-trapezoidal method $^{20,21}$ were derived. Samples for measurement of plasma brain natriuretic peptide (BNP) levels were taken a mean of 14 days and 6 months after AMI.

\section{Analysis of LV Function}

LV function was evaluated on the right anterior oblique views of left ventriculograms obtained a mean of 14 days and 6 months after AMI. The LV ejection fraction (LVEF) was determined by the area-length method as described by Sandler and Dodge ${ }^{2}$ Regional wall motion in the territory of the IRA was assessed by the centerline method and expressed as standard deviation (SD)/chord23 Infarct size was assessed by calculating the percentage of chords in the infarct zone $>2$ SDs below normal wall motion (percent abnormally contracting segment).

\section{Statistical Analysis}

Data are expressed as mean values $\pm \mathrm{SD}$ for continuous variables and as percentages for categorical variables. Continuous variables were compared by nonparametric tests (Mann-Whitney U test between groups). Chi-square analysis or Fisher's exact test was used to compare categorical variables. Differences were considered significant at $\mathrm{p}<0.05$. Statistical analysis was performed with StatView, version 5.0 (SAS Institute, Cary, NC, USA). The serial changes of the ST segment among groups were analyzed by mixed effect model. Data were analyzed using SAS (version 8.2, 


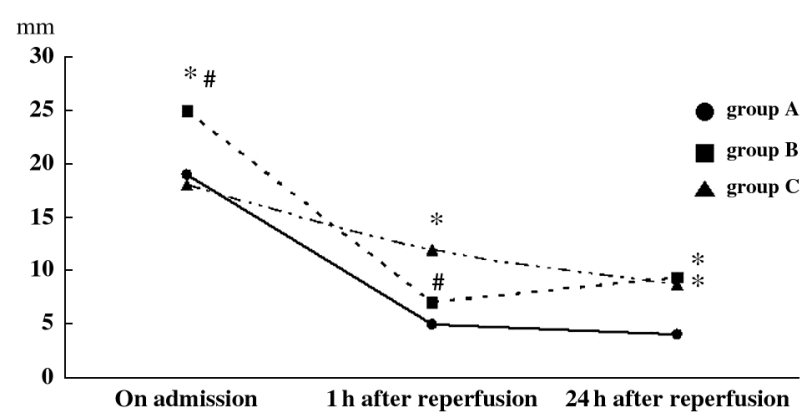

Fig 2. Course of the sum of ST-segment elevation from admission to $24 \mathrm{~h}$ after reperfusion. ${ }^{*} \mathrm{p}<0.01$ vs group $\mathrm{A},{ }^{\#} \mathrm{p}<0.01$ vs group $\mathrm{C}$.

SAS Institute).

Multivariate logistic regression analysis was used to identify clinical predictors of larger infarct size defined as the upper tertile of the AUC of CK-MB among the variables associated $(\mathrm{p}<0.05)$ with this index on univariate analysis. Odds ratios and 95\% confidence intervals were calculated. Data were analyzed using SPSS (Release 10, SPSS Inc, Chicago, IL, USA).

\section{Results}

Of the 164 patients, 119 had ST resolution, and 45 did not. Patients with ST resolution were classified according to the change in the $\sum S T$ value between 1 and $24 \mathrm{~h}$ after reperfusion: group A, 82 patients with ST resolution in whom $\sum \mathrm{ST}$ at $1 \mathrm{~h}$ was equivalent to or greater than $\sum \mathrm{ST}$ at $24 \mathrm{~h}$ $\left(\sum \mathrm{ST}-1 \mathrm{~h} \geq \sum \mathrm{ST}-24 \mathrm{~h}\right)$; and group B, 37 patients in whom in whom $\sum$ ST at $1 \mathrm{~h}$ was less than $\sum$ ST at $24 \mathrm{~h}\left(\sum \mathrm{ST}-1 \mathrm{~h}<\right.$ $\left.\sum \mathrm{ST}-24 \mathrm{~h}\right)$. The other patients without ST resolution comprised group C. Representative cases are shown in Fig 1.

\section{Patients' Characteristics}

There were no significant differences among the 3 groups with regard to age, sex, systolic blood pressure and heart rate on admission, previous angina, coronary risk factors, culprit lesion, collateral circulation, or multivessel disease. Medications at discharge were similar among the 3 groups. Patients who were in Killip $\geq 2$ were more frequent in groups $\mathrm{B}$ and C. Percutaneous coronary intervention was more frequently performed in groups B and C. The time from symptom onset to reperfusion was longest in group $\mathrm{B}$, and the
TIMI flow grade 0 or 1 at initial angiography was less frequent in group A (Table 1).

\section{Electrocardiographic Findings}

Both the number of leads with ST elevation $\geq 1 \mathrm{~mm}$ and the $\sum \mathrm{ST}$ value on admission were highest in group B. The $\sum$ ST value at $1 \mathrm{~h}$ after reperfusion was higher in group C than in the other 2 groups, but was similar in groups $\mathrm{A}$ and B (Fig 2). Additional ST-segment elevation immediately after reperfusion occurred more frequently in groups B and C. The QRS score on admission and at $1 \mathrm{~h}$ and $24 \mathrm{~h}$ after reperfusion was also higher in groups $\mathrm{B}$ and $\mathrm{C}$ than in group A (Table 2).

\section{Infarct Size and LV Function}

Peak CK, CK-MB activity, AUC for CK, CK-MB and CRP level 3 days after AMI were highest in group B, followed by group C, and lowest in group A. LVEF and regional wall motion were lowest and the percent abnormally contracting segment and LV end-diastolic volume index was largest in group B 6 months later. The plasma BNP level 6 months later was highest in group B, followed by group $\mathrm{C}$, and lowest in group $\mathrm{A}$ (Table 3 ).

\section{Predictors of Larger Infarct Size}

In the multivariate models, ST resolution with an increase in the $\sum$ ST between 1 and $24 \mathrm{~h}$, no ST resolution, Killip class $\geq 2$ on admission, culprit lesion (segment 6 ), and TIMI grade 0 or 1 on initial CAG were independent predictors of larger infarct size defined as the upper tertile of the AUC of CK-MB (Table 4). The other variables, including pre-infarction angina $(\mathrm{p}=0.06)$ and percutaneous coronary intervention $(\mathrm{p}=0.59)$, which were associated with larger infarct size on univariate analysis, were not significant predictors of larger infarct size.

\section{Discussion}

Most previous studies have found that ST resolution after reperfusion is associated with a smaller infarct size and better LV function in patients with AMI. In our study, however, patients in whom the $\Sigma$ ST increased between 1 and $24 \mathrm{~h}$ after reperfusion had a larger infarct size and poorer LV function, despite the presence of ST resolution according to the widely acceptable criteria $!^{5}$ These poorer results were similar to those in patients without ST resolu-

Table 2 Electrocardiographic Findings

\begin{tabular}{|c|c|c|c|c|}
\hline & $\begin{array}{c}\text { Group A } \\
\text { ST resolution } \\
\sum S T-1 h \geq \sum S T-24 h \\
(n=82)\end{array}$ & $\begin{array}{c}\text { Group } B \\
\text { ST resolution } \\
\sum S T-1 h<\sum S T-24 h \\
(n=37)\end{array}$ & $\begin{array}{c}\text { Group C } \\
\text { No ST resolution } \\
(n=45)\end{array}$ & $p$ value \\
\hline No. of leads with ST elevation $\geq 1 \mathrm{~mm}$ & $4.9 \pm 1.5$ & $5.6 \pm 1.3$ & $4.9 \pm 0.9$ & 0.025 \\
\hline \multicolumn{5}{|l|}{ Sum of ST-segment elevation: $\sum S T(\mathrm{~mm})$} \\
\hline On admission & $19 \pm 10$ & $25 \pm 10$ & $18 \pm 6$ & $<0.001$ \\
\hline $1 \mathrm{~h}$ after reperfusion & $5 \pm 4 *$ & $7 \pm 3 *$ & $12 \pm 4 *$ & $<0.001$ \\
\hline $24 \mathrm{~h}$ after reperfusion & $4 \pm 3 *$ & $9 \pm 3 * \dagger$ & $9 \pm 4 *$, & $<0.001$ \\
\hline \multicolumn{4}{|l|}{ QRS score } & $<0.001$ \\
\hline On admission & $2.3 \pm 2.4$ & $3.6 \pm 2.2$ & $3.9 \pm 2.7$ & 0.002 \\
\hline $1 \mathrm{~h}$ after reperfusion & $3.8 \pm 3.3$ & $6.6 \pm 2.7$ & $6.5 \pm 2.8$ & $<0.001$ \\
\hline $24 \mathrm{~h}$ after reperfusion & $4.1 \pm 3.4$ & $7.4 \pm 2.5$ & $7.3 \pm 3.1$ & $<0.001$ \\
\hline
\end{tabular}

Data are mean values $\pm S D$ or numbers $(\%)$ of patients.

${ }^{*} p<0.01$ vs value on admission, ${ }^{\dagger} p<0.05$ vs value at $1 \mathrm{~h}$ after reperfusion.

Abbreviations see in Table 1. 
Table 3 Infarct Size and LV Function at Discharge and 6 Months Later

\begin{tabular}{|c|c|c|c|c|}
\hline & $\begin{array}{c}\text { Group A } \\
\text { ST resolution } \\
\sum S T-1 h \geq \sum S T-24 h \\
(n=82)\end{array}$ & $\begin{array}{c}\text { Group B } \\
\text { ST resolution } \\
\sum S T-1 h<\sum S T-24 h \\
(n=37)\end{array}$ & $\begin{array}{c}\text { Group C } \\
\text { No ST resolution } \\
(n=45)\end{array}$ & $p$ value \\
\hline Peak $C K(\mathrm{mU} / \mathrm{ml})$ & $2,222 \pm 1,926$ & $4,578 \pm 2,176$ & $4,236 \pm 2,638$ & $<0.001$ \\
\hline Peak $C K-M B(m U / m l)$ & $205 \pm 170$ & $427 \pm 197$ & $393 \pm 276$ & $<0.001$ \\
\hline AUC for $C K(m U / m l \times h)$ & $65,992 \pm 49,714$ & $128,895 \pm 78,543$ & $118,956 \pm 72,242$ & $<0.001$ \\
\hline AUC for $C K-M B(m U / m l \times h)$ & $4,788 \pm 3,372$ & $8,588 \pm 3,137$ & $8,465 \pm 5,331$ & $<0.001$ \\
\hline CRP levels at 3 days after AMI $(\mathrm{mg} / \mathrm{dl})$ & $6.1 \pm 4.0$ & $8.6 \pm 4.6$ & $8.1 \pm 4.2$ & $<0.02$ \\
\hline \multicolumn{5}{|l|}{ At discharge } \\
\hline LV ejection fraction (\%) & $59 \pm 11$ & $51 \pm 10$ & $49 \pm 13$ & $<0.001$ \\
\hline Regional wall motion (SD/chords) & $-2.3 \pm 1.1$ & $-3.2 \pm 0.8$ & $-3.2 \pm 0.9$ & $<0.001$ \\
\hline Percent abnormally contracting segment & $22 \pm 17$ & $38 \pm 14$ & $38 \pm 14$ & $<0.001$ \\
\hline LV end-diastolic volume index $\left(\mathrm{ml} / \mathrm{m}^{2}\right)$ & $69 \pm 15$ & $77 \pm 15$ & $75 \pm 17$ & 0.08 \\
\hline Plasma BNP level $(\mathrm{pg} / \mathrm{ml})$ & $152 \pm 195$ & $288 \pm 276$ & $410 \pm 318$ & $<0.01$ \\
\hline \multicolumn{5}{|l|}{6 months later } \\
\hline LV ejection fraction (\%) & $62 \pm 9$ & $53 \pm 8$ & $54 \pm 12$ & $<0.001$ \\
\hline Regional wall motion (SD/chords) & $-2.1 \pm 1.0$ & $-3.1 \pm 0.5$ & $-2.9 \pm 0.9$ & $<0.001$ \\
\hline Percent abnormally contracting segment & $20 \pm 16$ & $40 \pm 9$ & $33 \pm 16$ & $<0.001$ \\
\hline LV end-diastolic volume index $\left(\mathrm{ml} / \mathrm{m}^{2}\right)$ & $65 \pm 15$ & $81 \pm 16$ & $77 \pm 20$ & $<0.001$ \\
\hline Plasma BNP level $(\mathrm{pg} / \mathrm{ml})$ & $50 \pm 39$ & $140 \pm 127$ & $126 \pm 147$ & $<0.03$ \\
\hline
\end{tabular}

Data are mean values $\pm S D$.

$L V$, left ventricular; $C K$, creatine kinase; $C K-M B$, myocardial bound fraction of $C K ; A U C$, area under the curve; $C R P, C$-reactive protein; BNP, brain natriuretic peptide. Other abbreviations see in Table 1.

Table 4 Multivariate Predictors of Larger Infarct Size Defined as the Upper Tertitle of the AUC of CK-MB

\begin{tabular}{|c|c|c|c|}
\hline & OR & $95 \% C I$ & $p$ value \\
\hline Group A & Referent & & \\
\hline Group B & 5.52 & $1.43-22.8$ & 0.013 \\
\hline Group C & 5.10 & $1.40-27.8$ & 0.022 \\
\hline Killip $\geq 2$ on admission & 9.04 & $1.02-80.8$ & 0.049 \\
\hline Culprit lesion (segment 6) & 4.01 & $1.85-13.8$ & 0.040 \\
\hline TIMI grade 0 or 1 at initial angiography & 9.56 & $2.32-39.3$ & 0.002 \\
\hline
\end{tabular}

OR, odds ratio; CI, confidence interval. Other abbreviations see in Tables 1,3.

tion. It is unclear why patients who had ST resolution with an increase in the $\Sigma$ ST between 1 and $24 \mathrm{~h}$ after reperfusion had poorer LV function. In this study, there were no significant differences in previous angina or collateral circulation among the 3 groups. However, patients who had ST resolution with an increase in $\Sigma$ ST between 1 and $24 \mathrm{~h}$ after reperfusion had a greater number of leads with ST-segment elevation $\geq 1 \mathrm{~mm}$, and higher $\sum \mathrm{ST}$ and QRS score on the admission ECG, suggesting more severe myocardial damage in a larger area at risk before reperfusion ${ }^{24,25} \mathrm{We}$ speculate that the mechanism underlying ST resolution differs between patients who had ST resolution with and without an increase in the $\Sigma$ ST between 1 and $24 \mathrm{~h}$ after reperfusion. Both patient groups had little residual ongoing ischemic myocardial injury $1 \mathrm{~h}$ after reperfusion, as reflected by ST resolution, 626 However, the myocardium has been already irreversibly damaged in the former, whereas the latter patients had a relatively large amount of viable myocardium. It is plausible that more severe, rapidly progressing myocardial damage before and during reperfusion may no longer cause ST-segment elevation after reperfusion. Furthermore, we speculate that the cause of ST-segment elevation $24 \mathrm{~h}$ later might be different from that at $1 \mathrm{~h}$ later in patients with ST resolution and an increase in the $\Sigma$ ST between 1 and $24 \mathrm{~h}$ after reperfusion. We found that such patients had higher CRP levels 3 days after AMI, suggesting a more intense inflammatory response after reperfusion. Higher CRP levels may simply reflect a larger infarct size; however,
Anzai et al suggested that the CRP level early after AMI reflects the healing of the infarct rather than the extent of myocardial necrosis 27,28 The excessive inflammatory response to the healing process of myocardial necrosis in these patients may be 1 of the factors affecting ST-segment elevation $24 \mathrm{~h}$ later. Pericarditis ${ }^{29}$ or infarct expansion ${ }^{30}$ has also been associated with ST-segment elevation. Shimizu et al reported that expansion of the infarcted portion might contribute to ST-segment re-elevation $3^{30}$ In our study, the LV end-diastolic volume index at discharge was largest in patients who had ST resolution with an increase in the $\Sigma$ ST between 1 and $24 \mathrm{~h}$ after reperfusion.

Recently, Brodie et al reported a poorer correlation between ST resolution and late cardiac mortality in anterior MI than in the non-anterior type ${ }^{12}$ and our results partly explain that finding because in the present study patients with ST resolution in whom $\sum S T$ increased between 1 and $24 \mathrm{~h}$ after reperfusion had a larger infarct size and poorer LV function.

\section{Study Limitations}

First, it was a small retrospective study of only patients with reperfused anterior wall AMI within $6 \mathrm{~h}$ of symptom onset. Second, we defined ST resolution according to the criteria proposed by Lemos et al ${ }^{15}$ which may be less objective and accurate than continuous ST-segment tracking with an automated analysis system. Continuous ST-segment tracking is accurate, but requires greater input from medi- 
cal and nursing staff and can lead to technical difficulties. We therefore evaluated ST resolution statically from 12-lead ECGs. Third, the presence of ischemia in the non-infarcted area might influence the degree of ST-segment deviation in the infarcted area on the admission ECG ${ }^{31}$ However, the rates of multivessel disease were not significantly different among the 3 groups.

\section{Conclusions}

Our findings suggest that ST-segment analysis $24 \mathrm{~h}$ after reperfusion can provide further information that complements the results of ST-segment analysis $1 \mathrm{~h}$ after reperfusion. Such information may be useful for identifying patients who are less likely to benefit from early reperfusion, even if they have ST resolution.

\section{References}

1. The TIMI study group. The Thrombolysis in Myocardial Infarction (TIMI) trial: Phase I findings. N Eng J Med 1985; 312: 923-936.

2. The GUSTO Investigators. An international randomized trial comparing four thrombolytic strategies for acute myocardial infarction. N Eng J Med 1993; 329: 673-682.

3. Grines CL, Browne KF, Marco J, Rothbaum D, Stone GW, O'Keefe $\mathrm{J}$, et al. A comparison of immediate angioplasty with thrombolytic therapy for acute myocardial infarction. N Eng J Med 1993; 328: 673-679.

4. Gibson CM, Cannon CP, Murphy SA, Ryan KA, Mesley R, Marble SJ, et al. Relationship of TIMI myocardial perfusion grade to mortality after administration of thrombolytic drugs. Circulation 2000; 101: $125-130$.

5. Tani S, Nagao K, Watanabe I, Kikushima K, Watanabe K, Anazawa $\mathrm{T}$, et al. Increasing well-preserved left ventricular function in hospital survivors with acute myocardial infarction. Circ J 2007; 71: $180-$ 185 .

6. Wada H, Yasu T, Kotsuka H, Hayakawa Y, Tsukamoto Y, Kobayashi $\mathrm{N}$, et al. Evaluation of transmural myocardial perfusion by ultra-harmonic myocardial contrast echocardiography in reperfused acute myocardial infarction. Cir J 2005; 69: 1041 - 1046.

7. Van't Hof AWJ, Liem A, de Boer M, Zijlstra F. Clinical value of 12lead electrocardiogram after successful reperfusion therapy for acute myocardial infarction: Zwolle Myocardial Infarction Study Group. Lancet 1997; 350: 615-619.

8. Claeys MJ, Bosmans J, Veenstra L, Jorens P, Raedt HD, Vrints CJ. Determinants and prognostic implications of persistent ST-segment elevation after primary angioplasty for acute myocardial infarction. Circulation 1999; 99: $1972-1977$.

9. Matetzky S, Novikov M, Gruberg L, Freimark M, Elian D, Novikov I, et al. The significance of persistent ST elevation versus early resolution of ST segment elevation after primary PTCA. J Am Coll Cardiol 1999; 34: $1932-1938$.

10. McLaughlin MG, Stone G, Aymong E, Mehran R, Lansky A, Grines $\mathrm{C}$, et al. Prognostic utility of comparative methods for assessment of ST segment resolution after primary angioplasty for acute myocardial infarction. J Am Coll Cardiol 2004; 44: 1215-1223.

11. Kosuge M, Kimura K, Ishikawa T, Endo T, Sugano T, Hibi K, et al. Reliability of Resolution of ST-segment elevation after coronary reperfusion in predicting myocardial salvage in anterior wall acute myocardial infarction. Am J Cardiol 2002; 90: 227-232.

12. Brodie BR, Stuckey TD, Hansen C, VerSteeg DS, Muncy DB, Moore $\mathrm{S}$, et al. Relation between electrocardiographic ST-segment resolution and early and late outcomes coronary intervention for acute myocardial infarction. Am J Cardiol 2005; 95: 343-348.

13. Ishihara M, Sato H, Tateishi H, Kawagoe T, Shimatani Y, Kurisu S, et al. Implications of prodromal angina pectoris in anterior wall acute myocardial infarction: Acute angiographic findings and long-term prognosis. J Am Coll Cardiol 1997; 30: 970-975.

14. Rentrop KP, Cohen M, Blanke H, Philips RA. Changes in collateral channel filling immediately after controlled coronary artery occlusion by an angioplasty balloon in human subject. J Am Coll Cardiol 1985; 5: $587-592$.

15. de Lemos JA, Antman EM, Giugliano RP, McCabe CH, Murphy SA, Van de Werf F, et al. ST-segment resolution and infarct-related artery patency and flow after thrombolytic therapy: Thrombolysis in Myocardial Infarction (TIMI) 14 investigators. Am J Cardiol 2000; 85: $299-304$.

16. Aldrich HR, Wagner NB, Boswick J, Corsa AT, Jones MG, Grande P, et al. Use of initial ST-segment deviation for prediction of final electrocardiographic size of acute myocardial infarctions. Am J Cardiol 1988; 61: 749-753.

17. Selvester RH, Wagner GS, Hindman NB. The Selvester QRS scoring system for estimating myocardial infarct size: The development and application of the system. Arch Inter Med 1985; 145: 1877-1881.

18. Juergens C, Femandes C, Hasche E, Meikle S, Bautovich G, Currie C, et al. Electrocardiographic measurement of infarct size after thrombolytic therapy. J Am Coll Cardiol 1996; 27: 617-624.

19. Miida T, Oda H, Toeda T, Higuma N. Additional ST-segment elevation immediately after reperfusion and its effect on myocardial salvage in anterior wall acute myocardial infarction. Am J Cardiol 1994; 73: $851-855$.

20. Vollmer RT, Christenson RH, Reimer K, Ohman EM. Temporal creatine kinase curves in acute myocardial infarction: Implications of a good empiric fit with the log-normal function. Am J Clin Pathol 1993; 100: 293-298.

21. Kusama I, Hibi K, Kosuge M, Nozawa N, Ozaki H, Yano H, et al. Impact of Plaque Rupture on Infarct Size in ST-Elevation Anterior Acute Myocardial Infarction. J Am Coll Cardiol 2007; 50: $1230-$ 1237.

22. Sandler H, Dodge HT. The use of single plane angiocardiograms for the calculation of left ventricular volume in man. Am Heart J 1968; 75: $325-334$.

23. Sheehan FH, Bolson EL, Dodge HT, Mathey DG, Schofer J, Woo HW. Advantages and applications of the centerline method for characterizing regional ventricular function. Circulation 1986; 74: $293-$ 305.

24. Hackworthy RA, Vogel NB, Harris PJ. Influence of infarct artery patency on the relation between initial ST segment elevation and final infarct size. Br Heart $J$ 1986; 56: 222-225.

25. Bar FW, Vermeer F, de Zwaan C, Ramentol M, Braat S, Simoons M, et al. Value of admission electrocardiogram in predicting outcome of thrombolytic therapy in acute myocardial infarction. Am J Cardiol 1987; 59: 6-13.

26. Dong J, Ndrepepa G, Schmitt C, Mehilli J, Schmieder S, Schwaiger $\mathrm{M}$, et al. Early resolution of ST-segment elevation correlates with myocardial salvage assessed by Tc-99m sestamibi scintigraphy in patients with acute myocardial infarction after mechanical or thrombolytic reperfusion therapy. Circulation 2002; 105: 2946-2949.

27. Anzai T, Yoshikawa T, Shiraki H, Asakura Y, Akaishi M, Mitamura $\mathrm{H}$, et al. C-reactive protein as a predictor of infarct expansion and cardiac rupture after a first Q-wave acute myocardial infarction. Circulation 1997; 96: 778-784.

28. Maekawa Y, Anzai T, Yoshikawa T, Asakura Y, Takahashi T, Ishikawa S, et al. Prognostic significance of peripheral monocytosis after reperfused acute myocardial infarction: A possible role for ventricular remodeling. J Am Coll Cardiol 2002; 39: 241-246.

29. Surawicz B, Lasseter KC. Electrocardiogram in pericarditis. Am J Cardiol 1970; 26: 471-474.

30. Shimizu M, Ishikawa K, Kanamasa K, Ogawa I, Koka H, Katori R. ST-segment re-elevation and left ventricular expansion soon after acute anterior myocardial infarction. Jpn Circ J 1992; 56: 235-242.

31. Tamura A, Kataoka H, Nagase K, MIkuriya Y, Nasu M. Clinical significance of inferior ST elevation during acute anterior myocardial infarction. Br Heart J 1995; 74: 611-614. 